\title{
Patterns of attendances to the hospital emergency eye care service: a multicentre study in England
}

\author{
Ian De Silva ${ }^{1 凶}$, Mervyn G. Thomas ${ }^{1,2}$, Amy-lee Shirodkar ${ }^{3}$, Helen J. Kuht ${ }^{1,2}$, Jae Yee Ku ${ }^{4,5}$, Ritu Chaturvedi ${ }^{4}$, Freddy Beer ${ }^{6}$, \\ Radhika Patel ${ }^{7}$, Romeela Rana-Rahman ${ }^{8}$, Sarah Anderson ${ }^{9}$, Polly Dickerson ${ }^{10}$, Francine Walsh ${ }^{11}$, Ben While ${ }^{7}$, Lucy Clarke $^{8}$, \\ Dilani Siriwardena ${ }^{3}$, Felipe Dhawahir-Scala ${ }^{4}$, BEECS Study Group*, John Buchan ${ }^{12,13}$ and Seema Verma ${ }^{14}$
}

(c) Crown 2021

BACKGROUND/OBJECTIVES: To characterise the patterns of presentation and diagnostic frequencies in Hospital Emergency Eye Care Services (HEECS) across 13 hospitals in England.

METHODS: Retrospective, cross-sectional, observational multi-centre $(n=13)$ study to assess HEECS attendances over a 28 -day study period. Data derived included: number of consecutive attendances, patient demographics and diagnoses. Age and gender variations, the impact of day of the week on attendance patterns, diagnostic frequencies and estimates of the annual incidence and attendance rates were evaluated.

RESULTS: A total of 17,667 patient (mean \pm standard deviation age $=49.6 \pm 21.8$ years) attendances were identified with an estimated HEECS annual new attendance rate of 31.0 per 1,000 population. Significantly more females (53\%) than males (47\%) attended HEECS $(p<0.001)$. Female attendances were $13 \%$ higher in those $\geq 50$ years of age. Weekends were associated with a significant reduction in attendances compared to weekdays $\left(x^{2}=6.94, p<0.001\right)$. Among weekdays, Mondays and Fridays were associated with significantly higher attendances compared with midweek $\left(x^{2}=2.20, p=0.032\right)$. Presenting pathologies involving the external eye, cornea and conjunctiva accounted for $28.6 \%$ of the caseload.

CONCLUSION: This is the largest multicentre study assessing attendance patterns in HEECS in England. We have, for the first time, observed a "weekend effect" in relation to attendance to HEECS. Differences in health-seeking behaviour and lack of awareness of HEECS weekend services may be partly attributed to the differences observed. Our findings, along with the type of presentations, have the potential to guide commissioners with future planning of HEECS.

Eye (2022) 36:2304-2311; https://doi.org/10.1038/s41433-021-01849-8

\section{INTRODUCTION}

Over the past two decades, there has been a rise in demand for ophthalmology led Hospital Emergency Eye Care Services (HEECS) in England [1]. London's two largest HEECS units, Moorfields Eye Hospital and the Western Eye Hospital, have reported an increase in annual attendance by $7.9 \%$ and $9.6 \%$ per year respectively $[2,3]$. The increase in attendance in HEECS have been attributed to (a) increasing population size and ageing demographic, (b) further indications for treatment, (c) defensive medico-legal practice amongst community practitioners [4], (d) changes to service accessibility and (e) patient health-seeking behaviours [5].

Ophthalmology-led HEECS within the NHS can be accessed through an appointment-based (AB) system, a walk-in (WI) service, or a combination of the two. Access to HEECS is predominantly available during extended outpatient clinic hours. Outside of these hours, patients often have access to on-call services $[5,6]$.

Community-based optometry schemes have been made available in some regions of UK. Examples include the Primary Eye-care Acute Referral Scheme, Acute Community Eye-care services, and Minor Eye Conditions Services. The overarching aims of these schemes are to provide patients with access to an eye care professional in their local area, subsequently reducing the burden of low-risk pathology presentations on HEECS [7].

Information regarding the nature and patterns of demand on HEECS is essential for planning acute eye care service provision. There is limited published data from the UK, and previous reports

\footnotetext{
${ }^{1}$ Department of Ophthalmology, University Hospitals of Leicester, Leicester Royal Infirmary, Leicester LE1 5WW, UK. ${ }^{2}$ The University of Leicester Ulverscroft Eye Unit, Department

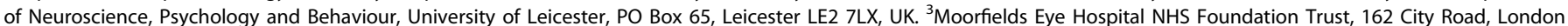

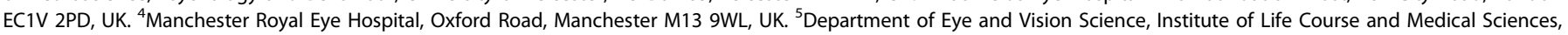

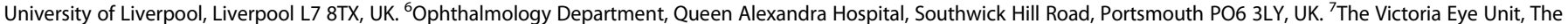

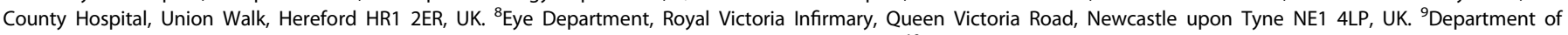

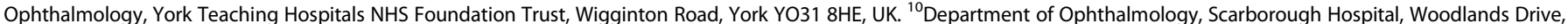

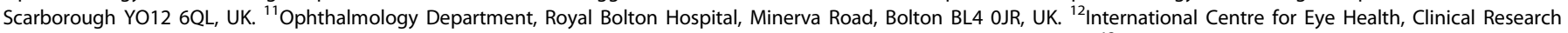

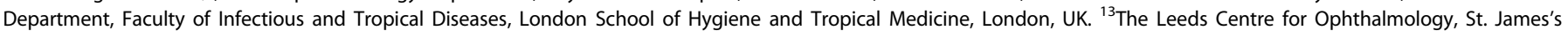

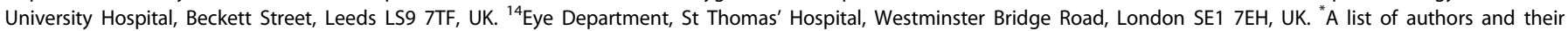
affiliations appears at the end of the paper. ${ }^{凶}$ email: iandsmail@aol.com
}

Received: 18 March 2021 Revised: 9 October 2021 Accepted: 8 November 2021

Published online: 30 November 2021 


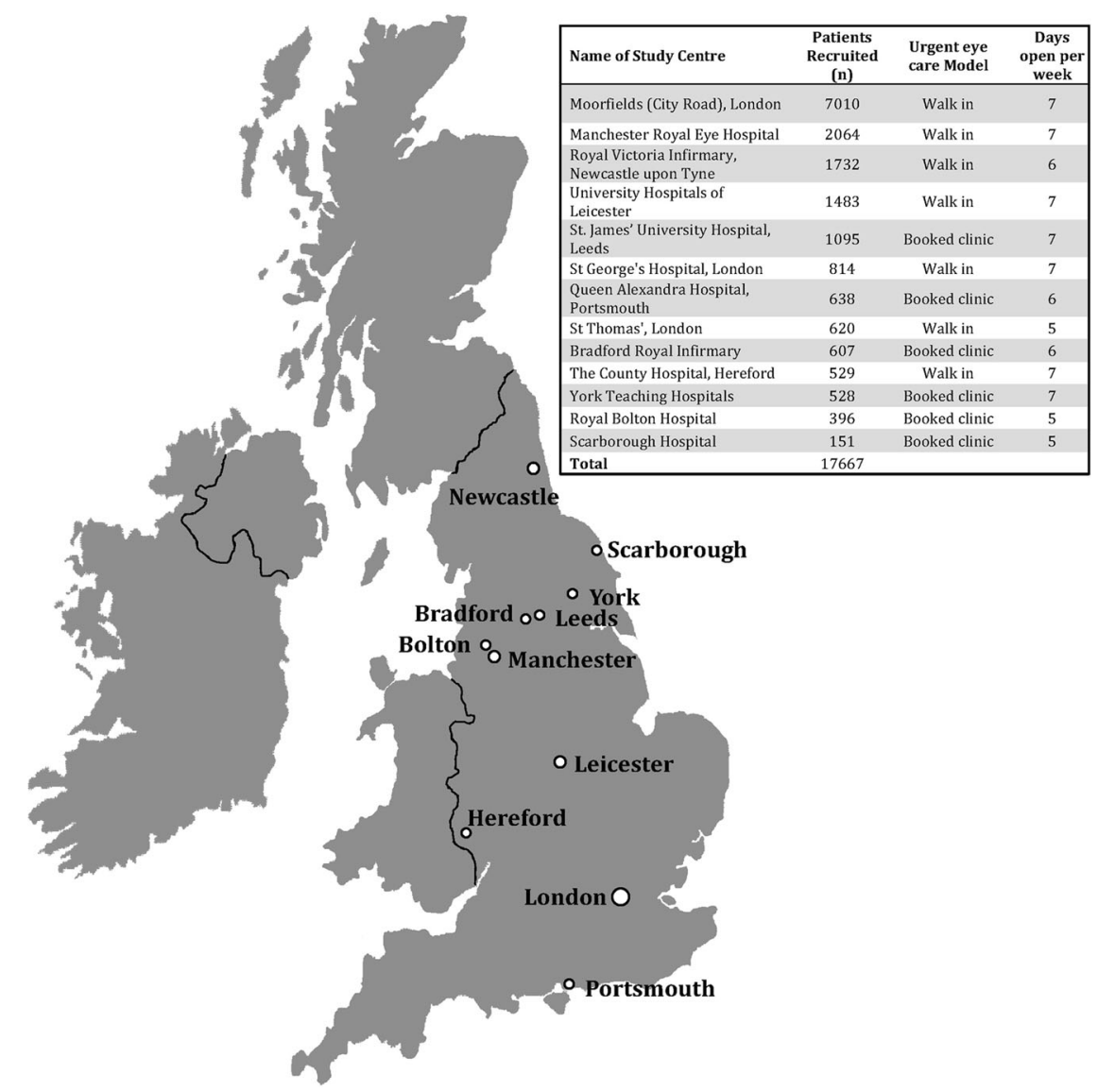

Fig. 1 A geographical representation of all sites that took part in the English Emergency Eyecare (Triple E) study in England including baseline details about each centre. Figure 1 is illustrated by the first author of this paper, Mr. I De Silva, who has given permission for use in this paper.

have been confined to single centre studies [8]. Therefore, this multi-centre study, utilising data from across England, aims to describe the demographic and diagnostic patterns in acute eye care presentations to better understand demands on HEECS and to facilitate the commissioning and provision of emergency eye care.

\section{METHODOLOGY}

This Triple E (English Emergency Eye-care) study is a retrospective, cross-sectional, observational multicentre study, conducted by members of the British Emergency Eye Care Society (BEECS) across 13 different ophthalmology-led HEECS centres in England (Fig. 1). The Triple E study involved a convenience sample of centres in England selected based on the engagement of clinicians from those locations in BEECS. We aimed to include a variety of sizes of units, defined by the number of attendances, and service designs. This included 7 walk-in centres and 6 centres with booked or acute referral clinics. There were 5 large-sized (> 1000 average attendances per month), 6 mid-sized (between 500 and 1000 average attendances per month) and 2 small-sized ( $<500$ average attendances per month) centres. The BEECS study group defined a 28-day study period from 6th January 2020 to 2nd February 2020, inclusive. All participating sites collected data for consecutive patient attendances in their HEECS during this period for face-toface consultations. Each study site had its own method of data recording and diagnostic categories. Data recording was found to be either solely electronic notes, paper-based or a hybrid system of using both paper documentation and electronic record of diagnoses and activity letters. Standardisation of data collection across different sites was achieved through the distribution of a centralised proforma with pre-defined diagnoses. Sites collected information on patient age, gender, date and time of attendance and diagnosis given at that consultation. Diagnoses were further sub-grouped according to their respective subspecialist categories (supplementary figure 1). Each centre also provided their respective monthly attendances during the previous three years between January and April. Each HEECS centre sought approval from its local research and development department.

Centres were invited to include either new patients or a combination of new patients and urgent follow-up patients. Where possible, centres were advised to categorise each attendance to be either new or follow-up. Collected data were anonymised and then cleaned by the study investigators. To ensure standardisation of disease definitions, diagnoses and subspeciality categorisation, two independent external data validation tests were conducted. When multiple diagnoses were present, only the main diagnosis for their presenting complaint was attributed. The validation process involved evaluating the electronic data submitted by each centre for every patient to ensure that they correctly defined the appropriate diagnosis and diagnosis subcategory. In cases with insufficient data, the investigators for those centres were approached for further clarification.

To estimate the annual attendance rate, only data of new patients of 'walk in' HEECS were used. $A B$ attendances were excluded from this calculation as their attendances are determined by the number of available clinical appointments. This provided the number of new $\mathrm{Wl}$ attendances in the 28-day period. The annual number of HEECS attendances were derived by extrapolating the 
(A)

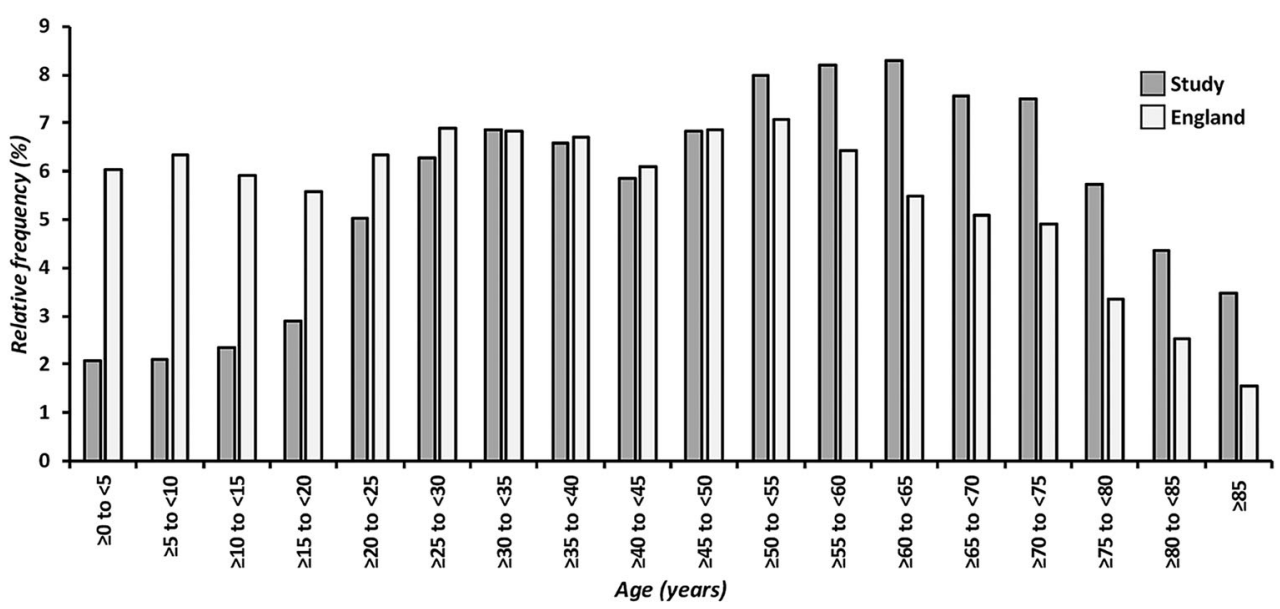

(B)

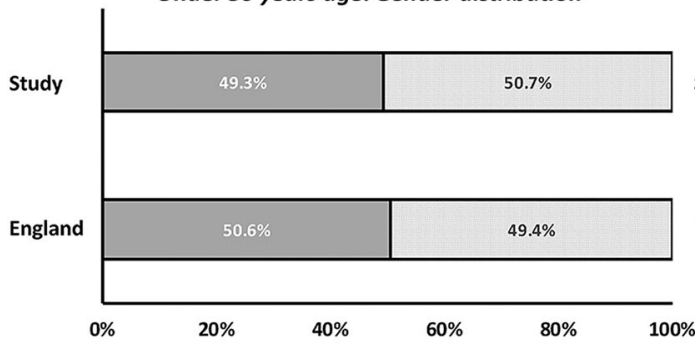

(C)

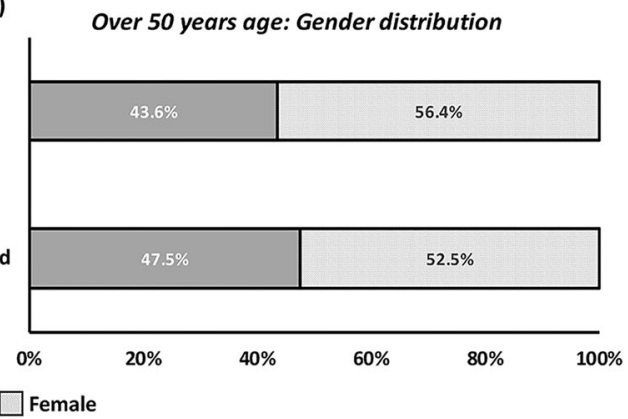

Fig. 2 Age and gender distribution of attendees in the English Emergency Eye Care (Triple E) study and office for national statistics (ONS) data. A The percentage frequency of attendances for each 5-year age group. It also highlights the percentage frequency of the population of England for each 5-year age group as a comparator. B, C The proportion of males and females in the study attendees in comparison to the general population of England for those under 50 years of age and for those aged 50 and over, respectively.

number of HEECS attendances for a year, based on this 28-day data. The catchment population of HEECS was derived from estimating the population served by each of the study centres across England. This was based on the relative general A\&E attendances at each of the centres in comparison to the total A\&E attendances in England (supplementary table 1) [9]. Moorfields Eye Hospital was excluded from these calculations since it was a standalone centre without a general A\&E service. The annual age-specific attendance rates were estimated using demographic data from the Office for National Statistics (ONS) [10].

Only centres with a seven-day WI service with the same opening hours irrespective of the day of the week were used to assess the effect of the day of the week on the number of attendances. We further divided the data into weekdays (Monday to Friday) and weekends (Saturday and Sunday).

\section{Statistical analyses}

Statistical analysis was performed with SPSS software (IBM Corp. Released 2019. IBM SPSS Statistics for Windows, Version 26.0. Armonk, NY: IBM Corp). Shapiro-Wilk test was used to test for normality of the data. Gender and age in the study population and general population of England (derived from the latest update of the ONS) [10] demonstrated non-normally distributed data. Rates of attendances over the seven-day week demonstrated normally distributed data.

The Pearson chi-squared test $\left(x^{2}\right)$ was used to assess the relative proportions between the following groups: (a) males and females in the study population compared to the general population in England (ONS data); (b) age and gender proportions for each subspecialty group.
An unpaired $t$-test was used to examine differences between the mean attendances on weekdays and weekends. Similarly, an unpaired $t$-test was used to test our null hypotheses that there were no differences in mean attendances for Monday and Friday in comparison to the midweek (Tuesday, Wednesday, and Thursday). Data was transformed for each day attendance as a percentage of total attendance per week. All analyses were considered significant at a type 1 probability value of $p<0.05$.

\section{RESULTS}

\section{Age and gender}

During the 28-day study period, a total of 17,667 patients (mean \pm standard deviation age $=49.2 \pm 21.8$ years) attended HEECS across all sites. A higher percentage of females (53.3\%) presented to HEECS compared to males (46.7\%). This proportion of females presenting to HEECS during the study period was significantly higher in comparison to that reported for the general population ONS data $\left(x^{2}=52.9, p<0.001\right)$. The preponderance of females in the HEECS study amongst those $\geq 50$ years was also found to be significant $\left(X^{2}=34.4, p<0.001\right)$ showing a difference of $13 \%$ more females than males in our study. There were no significant differences in the proportion of males and females aged $<50$ years attending HEECS when compared to the general population ONS data $\left(x^{2}=3.35, p=0.07\right)$. Figure 2 illustrates the overall demographic data based on age and gender.

We estimated that the population served by the 12 centres (excluding Moorfields Eye Hospital) to represent $\sim 9.3 \%$ of the total population in England. The estimated annual WI HEECS attendance rate was 31.0 per 1000 population for new patients. This 

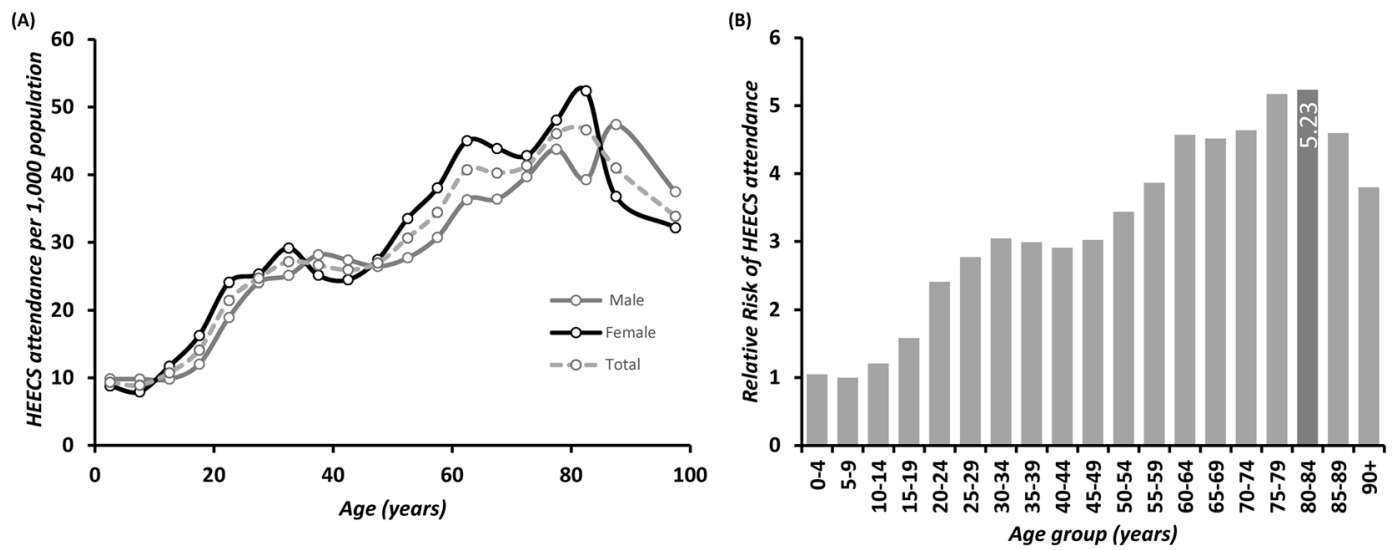

Fig. 3 Hospital Emergency Eye Care Service (HEECS) attendance rates. A The annual age specific attendance rate per 1000 population. Each data point represents the attendance rate for each 5-year group plotted on the mean age of that group; B The relative risk of HEECS attendance for each 5-year group compared to the lowest attendance rate age group (5-9 age group).

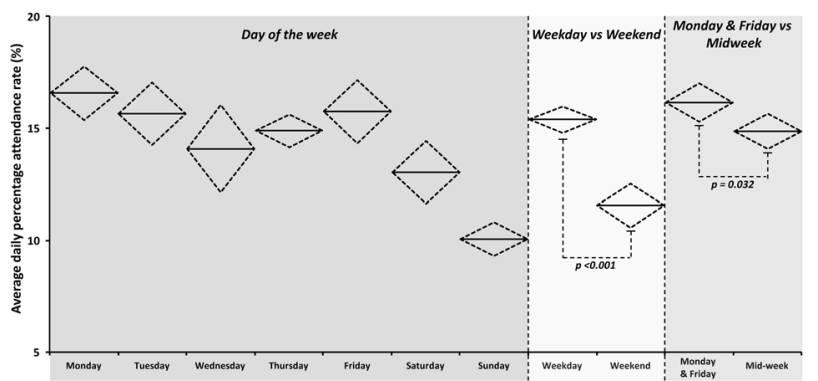

Fig. 4 Percentage of patient attendances based on the day of the week with mean \pm SD. Only data from walk in eye casualty services open seven days a week with approximately similar opening hours irrespective of the day of the week were used. The left section highlights an assessment of all days of the week. The middle section compares average daily weekday attendances to weekend attendances. Finally, the section on the right compares average daily attendances of Mondays and Fridays in comparison to midweek days.

was based on three WI HEECS services representing 5057 attendances over the 28-day period.

The highest annual attendance rate was observed in the 80-84year age group with approximately a five-fold higher rate of attendance compared with those aged in the 5-9-year group, who had the lowest attendance rate. Figure 3 illustrates the agespecific annual attendance rates per 1000 population.

\section{Attendance by 'Day of the week'}

The highest proportion of attendances were on Mondays (16.6\% of total week caseload) and Fridays (15.7\%). The lowest proportion of attendances were on Sundays (10.0\%) and Saturdays (13.0\%) (Fig. 4). Overall, a significant reduction in attendance was observed on weekends in comparison to weekdays $(t=-6.94$, $p<0.001$ ) (Fig. 4). Furthermore, a significant increase in attendance was observed on Mondays and Fridays compared to other weekdays ( $t=-2.20, p=0.032$ ) (Fig. 4).

\section{Attendance by subspecialty}

Of the total 17,667 HEECS attendances observed across the 28-day study period, $15,400(87.2 \%)$ had sufficient diagnostic data to enable appropriate subspecialty grouping. Cases with insufficient data and patients that self-discharged prior to the clinical consultation were excluded from this sub-study. External eye disease, cornea, and conjunctiva group $(n=4404)$ were the most frequently presenting diagnoses, representing $28.6 \%$ of cases. Trauma $(n=2110)$, adnexal $(n=2094)$ and vitreoretinal $(n=1648)$ conditions followed, representing $13.7 \%, 13.6 \%$, and $10.7 \%$ of attendances, respectively. Subspecialties of 'other' and 'glaucoma' groups had the least frequent attendances with the latter 'glaucoma' group $(n=323)$ representing just $2.1 \%$ of all case attendances to HEECS. Table 1 illustrates the breakdown of attendance based on subspecialties.

Our results showed that in all but one subgroup category there was a statistically significant difference in the proportion of attendances between those $<50$ and those $\geq 50$ years old. The most significant difference was observed in vitreoretinal cases (3.3\% vs. $16.6 \%$ respectively, $\left.X^{2}=486.09, p<0.001\right)$ and trauma ( $21.1 \%$ vs. $7.9 \%$ respectively, $\left.X^{2}=369.92, p<0.001\right)$. The exception to these observed differences was in the uveitis group, where a near equal proportion of cases were seen in both age groups; $<50$ groups $(9.6 \%)$ and the $\geq 50$ groups $(9.0 \%)\left(x^{2}=1.03, p=0.310\right)$. Subgroup analysis by age $\geq 50$ years and gender are also highlighted in Table 1.

There were significantly more proportion of female patients (7.4\%) presenting with neuro-ophthalmological conditions than male patients $(4.6 \%)\left(x^{2}=51.46, p<0.001\right)$. Furthermore, there were significantly more proportion of female patients $(6.7 \%)$ than male patients $(4.8 \%)$ in the 'no ocular abnormality detected' group $\left(x^{2}=23.46, p<0.001\right)$.

Seventy percent of all trauma cases were observed in patients $<50$ years old and this rose to $83.6 \%$ when including all patients $<60$ years old. There were significantly more males $(18.7 \%)$ who presented with trauma compared to females $(9.2 \%)\left(x^{2}=292.64\right.$, $p<0.001)$. Trauma-related pathology was the most common presentation in males $<50$ years old $(29.6 \%)$. The ratio of males: females $\leq 16$ years presenting with trauma was 1.32:1.

Comparatively, in females $<50$ years old, trauma accounted for only $13 \%$ of presentations while almost half of presentations were due to adnexal and external eye diseases (48.1\%).

\section{DISCUSSION}

To our knowledge, we have reported the largest multicentre observational study in England assessing clinical presentations to HEECS. This Triple E study highlights the spectrum of diagnoses and demographics of patients accessing HEECS during a 4-week period in 2020 across 13 different sites in England. To date, literature reporting the annual attendance rates for HEECS has been scarce. Based on a sample of 28 days, we have estimated the annual attendance of new HEECS presentation to be 31 per 1000 population. Our results corroborate previous estimates of new eye casualty attendances, which have been between $20-30$ per 1000 population per year [11]. 
Table 1. Presentations according to subspecialties, gender, and age with $x^{2}$ and $p$ values.

\begin{tabular}{|c|c|c|c|c|c|}
\hline $\begin{array}{l}\text { Subspecialty Category } \\
(n=15,400)\end{array}$ & $\begin{array}{l}\text { Number of } \\
\text { attendances (\%) }\end{array}$ & $\begin{array}{l}\text { Male (\% of male } \\
\text { attendances) }\end{array}$ & $\begin{array}{l}\text { Female (\% of female } \\
\text { attendances) }\end{array}$ & $x^{2}$ & $p$ \\
\hline 2 - External/Cornea/Conjunctiva & $4400(28.6 \%)$ & $26.8 \%$ & $30.1 \%$ & 20.92 & $<0.001$ \\
\hline 4 - Uveitis & $1458(9.5 \%)$ & $9.0 \%$ & $9.9 \%$ & 3.33 & 0.068 \\
\hline 5 - Medical Retina & $658(4.3 \%)$ & $4.5 \%$ & $4.1 \%$ & 1.47 & 0.226 \\
\hline $\begin{array}{l}8 \text { - Post-op/post intervention } \\
\text { complication/issue }\end{array}$ & $642(4.2 \%)$ & $4.2 \%$ & $4.1 \%$ & 0.21 & 0.647 \\
\hline 9 - Other & $226(1.5 \%)$ & $1.5 \%$ & $1.5 \%$ & 0.00 & 0.971 \\
\hline 10 - Trauma & $2103(13.7 \%)$ & $18.7 \%$ & $9.2 \%$ & 292.64 & $<0.001$ \\
\hline 11 - No ocular abnormality & 897 (5.8\%) & $4.8 \%$ & $6.7 \%$ & 23.43 & $<0.001$ \\
\hline \multicolumn{2}{|l|}{3 - Glaucoma } & $1.1 \%$ & $3.2 \%$ & 54.11 & $<0.001$ \\
\hline \multicolumn{2}{|l|}{4 - Uveitis } & $9.6 \%$ & $9.0 \%$ & 1.03 & 0.310 \\
\hline \multicolumn{2}{|l|}{5 - Medical Retina } & $2.0 \%$ & $6.8 \%$ & 134.31 & $<0.001$ \\
\hline \multicolumn{2}{|l|}{6 - Vitreo-retinal } & $3.3 \%$ & $16.6 \%$ & 486.09 & $<0.001$ \\
\hline \multicolumn{2}{|l|}{7 - Neuro-ophthalmology } & $7.9 \%$ & $6.1 \%$ & 13.43 & $<0.001$ \\
\hline \multicolumn{2}{|c|}{8 - Post-op/post intervention complication/issue } & $1.6 \%$ & $6.9 \%$ & 168.78 & $<0.001$ \\
\hline \multicolumn{2}{|l|}{9 - Other } & $0.8 \%$ & $2.1 \%$ & 30.58 & $<0.001$ \\
\hline \multicolumn{2}{|l|}{10 - Trauma } & $21.1 \%$ & $7.9 \%$ & 369.92 & $<0.001$ \\
\hline \multicolumn{2}{|l|}{11 - No ocular abnormality } & $8.0 \%$ & $5.5 \%$ & 26.70 & $<0.001$ \\
\hline
\end{tabular}

Compared to the ONS data, our results showed that the largest proportion of patients accessing HEECS were between those aged 50-90 years. This in part can be explained by the increased presentations of ocular emergencies in the older age groups such as vitreoretinal, retinal vascular and macular disorders $[5,12,13]$. After adjusting for the population differences within each age group, the highest attendance rate was observed in the 80-84year age group.

We observed a significantly greater proportion of female patients accessing HEECS than male patients in comparison to the gender difference in the general population. One study of urgent eye care services [14] and another review of patients attending general practice in the UK [15] found similar female preponderances. After allowing for the gender difference in the general population of England, we found that female patients were $17 \%$ more likely to present to HEECS in those $\geq 50$ years of age.

The observed gender differences may be partly attributed to the differences in health seeking behaviours between males and females [15-18]. Further studies would be required to assess if the lower attendance rate in males $\geq 50$ years of age puts them at greater risk of sight threatening harm than females. Conversely, our findings may represent an underutilisation of community eye care services by females, or a health education need to address the greater number of females presenting to HEECS for low sightthreatening risk presentations that may be appropriately selfmanaged. A secondary consequence of sight-threatening disease includes the significant impact on the patients' social and psychological wellbeing and the impact on the wider community, and evaluation of gender differences in this would also be useful [19-21].

To our knowledge, this study is the first to objectively report on the impact of the day of the week on emergency eye care attendances and an apparent 'weekend effect', where there was a significant reduction in attendance on weekends compared to weekdays. Previous studies reporting trends in general A\&E attendances showed the highest attendance was on a Monday ( $10 \%$ higher than any other day) and lowest on a Friday, with no significant difference in the number of attendances on weekends compared to the weekdays $[22,23]$. Anecdotal experience from the authors suggested the contrary in that acute eye departments seem less busy over the weekend. Our observation of an apparent 'weekend effect' would need further research to fully understand these findings. One explanation may be a perception of the lack of awareness regarding the availability of HEECS during the weekend. This may change health-seeking behaviours on a weekend where patients may access alternative sources such as a local pharmacy, optometrist or present earlier or later, avoiding weekends. Furthermore, reduced access to the general practitioner or general optometric services that act as primary referral sources to a portion of HEECS may be a factor over weekends, with some patients delaying presentation to primary care until the weekday. Conversely, this may also increase weekend attendances due to the absence of alternative primary care services. This may be especially important for specific sight-threatening conditions where delay in presentation may be detrimental. Reduced access of HEECS in nearby regions during the weekend may also explain higher attendances on weekends. Further research to study the impact of our findings is required to determine the sight-threatening risk of the reduced presentation over the weekend. This may highlight an important public health message for patients with significant visual symptoms to present as early as possible including over the weekend, as well as commissioning the correct services and allocation of staff to ensure service availability for patients presenting with an emergency eye condition at weekends.

Anterior segment disease (anterior segment trauma, external eye conditions, adnexal and anterior uveitis) was the most 
common collection of diagnoses made in the HEECS (65.3\%) during the study period. This finding is consistent with previous studies, where anterior segment diseases were diagnosed in $55-75 \%$ of all presentations [8, 14]. We identified five-fold higher vitreoretinal presentations in both genders $\geq 50$ years old. This reflects known evidence of a higher prevalence of vitreoretinal conditions in the older population. Less substantial higher attendance rates were found in patients $\geq 50$ years presenting with glaucoma, medical retina, and post-operative/treatment conditions. Our findings can help to prepare disease-specific resources available required to meet the demand in HEECS.

Strategies to reduce patient attendance at HEECS can include (a) effective triaging, (b) appropriate training of general A\&E staff and community general practitioners, and (b) the utilisation of community optometry schemes $[8,24,25]$.

Previous studies have identified that a significant proportion of anterior segment diseases may be suitable for management outside the hospital eye service setting [8]. A study involving 2123 patients in the minor eye conditions scheme in Lambeth \& Lewisham over 12 months showed that $>75 \%$ of patients were managed in the community alone [7]. No abnormality was identified in $6 \%$ of attendances to HEECS in this study which may be a further group of cases to potentially be managed in the community, thus reducing the demand on HEECS. More detailed diagnostic information on the presentations and suitability of cases to be managed in the community setting would be required in future studies.

We found a higher proportion of trauma in young males, which was consistent with findings in other published studies [26-30]. A large study on ocular injuries in the USA showed that $66 \%$ of patients were males and $91 \%$ were $<60$ years old [31]. In Scotland, a study on serious ocular trauma showed that $85 \%$ of cases were males [29]. These findings may be attributed to the increased prevalence of manual labour vocations in males compared to females [32]. One study proposed that the gender segregation of occupations and the gender division of labour within specific occupations can place men at a greater risk of injury compared to female counterparts [33]. In a study of ocular injuries in children, the difference in gender prevalence was attributed to boys being more adventurous or possibly displaying more aggressive behaviours [34].

Our study design aimed at capturing acute presentations to the eye casualty clinics, therefore a limitation is this does not represent all acute ocular presentations to hospital services. Attendances "out of hours" that may have been managed in the emergency department or referrals to other urgent "fast-track clinics" will be missed in our data capture process. The authors did not include the above as the purpose and focus of the Triple $E$ study was to assess the presentations to the HEECS (WI or AB) to evaluate the service demand. Another limitation of our study relates to the calculation of the HEECS attendance rates. Several assumptions were made when calculating the population served by the NHS trusts in this study and the relative age specific attendance rates. We assumed that our sample 28- day study period was a reflective representation of HEECS attendances across the year. We validated this annual HEECS attendance by using the monthly attendances for the previous two years between January and April for each site. The difference between the two methods was less than $1 \%$.

Furthermore, we assumed the population demographics in the study centres were reflective of the distribution in England and the general A\&E attendance rate was the same across England. The authors investigated alternative methods of estimating catchment areas, however identified the calculation used in this study to provide the best representation of the study population.

The authors acknowledge that these results are based on the chosen convenience sample and results from a single 28-day period. A longer duration would have been chosen had it not been for the resource challenge of collecting more data ensuring appropriate diagnosis definition and data validation for these. The study design was chosen to try and achieve a balance of different sized units and chose the specific month of January, as we found these to be more reflective of annual attendance patterns. The results on weekend and day of the week attendances presented do represent a significant contribution from city road, Moorfields. Sub-group analysis excluding this centre yielded similar results and the same conclusions. Finally, from conducting the study, the authors noted that HEECS centres have different ways of recording data, coding diagnoses and availability of these data for retrospective analysis. Considerable time and resources were taken to reassess each of the cases for the purposes of this study. The authors would conclude that future studies and analysis would be helped by the presence of a nationwide system of recording attendances and diagnoses in HEECS across the UK.

Since the outbreak of the coronavirus disease (COVID-19) there has been the implementation of local Covid-19 Urgent Eye care Services (CUES). The original intention and success of the scheme was to reduce the burden on secondary healthcare services, allowing staff and resources to be redirected to manage the increased admissions due to the pandemic [35]. The impact of CUES would be of great interest to further research in this field. Although CUES continues to provide alternative paths for HEECS patients to utilize, the current trend and thoughts amongst the authors is that most HEECS services are seeing attendances return to pre-pandemic levels.

In conclusion, this multi-centre study undertaken by BEECS highlights the attendance rates of HEECS and differences in presentation based on age, gender, day of the week and diagnosis subgroup. This will guide service delivery including staff allocation based on local demographics and day of the week. Moreover, targeted training with emphasis on anterior segment disorders both within HEECS and community-based triaging services will help reduce burden of presentations and follow-ups to hospitals. With an increase in community-based optometry schemes and the advent of teleophthalmology, our dataset will provide the foundation for commissioning and establishing the best infrastructure to screen and triage for the majority of the ocular emergency presentations.

\section{Summary}

What was known before

- Most hospital urgent eyecare presentations are due to anterior segment disease.

- Most young males present with trauma-related diagnoses.

What this study adds

- Identifies the significant gender difference in attendances to the hospital urgent eyecare service in males $\geq 50$ years of age.

- Significantly less people present over the weekend than the weekday with Sunday being the quietest day. Mondays and Fridays are the two busiest days.

- Reinforces anterior segment related disease to be the most prevalent group of presentations.

\section{REFERENCES}

1. Siempis T. Urgent Eye Care in the UK increased demand and challenges for the future. Med Hypothesis Disco Innov Ophthalmol. 2014;3:103-10.

2. Smith HB, Daniel CS, Verma S. Eye casualty services in London. Eye (Lond). 2013;27:320-8.

3. NHS England UK. A\&E Attendances and Emergency Admissions 2020-21 2020 [Available from: https://www.england.nhs.uk/statistics/statistical-work-areas/aewaiting-times-and-activity/ae-attendances-and-emergency-admissions-2020-21/]. 
4. Dyer C. Court overturns optometrist's conviction for gross negligence manslaughter. BMJ 2017;358:j3749.

5. Buchan JC, Barnes B, Cassels-Brown A, Chang BY, Harcourt J, Pilling RF, et al. The urgent need to develop emergency EYE care in the UK: the way forward? Eye (Lond). 2017;31:1515-8.

6. The Royal College of Ophthalmologists. The way forward: Emergency eye care 2017 [Available from: https://www.rcophth.ac.uk/wp-content/uploads/2015/10/ RCOphth-The-Way-Forward-Emergency-Eye-Care-Summary-300117.pdf].

7. Konstantakopoulou E, Harper RA, Edgar DF, Larkin G, Janikoun S, Lawrenson JG. Clinical safety of a minor eye conditions scheme in England delivered by community optometrists. BMJ Open Ophthalmol. 2018;3:e000125.

8. Hau S, loannidis A, Masaoutis P, Verma S. Patterns of ophthalmological complaints presenting to a dedicated ophthalmic accident \& emergency department: Inappropriate use and patients' perspective. Emerg Med J. 2008;25:740-4.

9. Activity HAaE. Hospital Accident \& Emergency Activity 2018-19 2019 [Available from: https://digital.nhs.uk/data-and-information/publications/statistical/hospitalaccident-emergency-activity/2018-19].

10. Activity HA\&E. Hospital Accident \& Emergency Activity 2018-19 2019 [Available from: https://digital.nhs.uk/data-and-information/publications/statistical/hospitalaccident-emergency-activity/2018-19].

11. Ophthalmologists TRCo. Ophthalmic Service Guidance: Emergency eye care in hospital eye units and secondary care. 2017 [Available from: https://www. rcophth.ac.uk/wp-content/uploads/2017/08/Emergency-eye-care-in-hospital-eyeunits-and-secondary-care.pdf].

12. Evans JR, Fletcher AE, Wormald RP. Assessment MRCTo, Management of Older People in the $C$. Causes of visual impairment in people aged 75 years and older in Britain: An add-on study to the MRC Trial of Assessment and Management of Older People in the Community. Br J Ophthalmol. 2004;88:365-70.

13. Thapa SS, Thapa R, Paudyal I, Khanal S, Aujla J, Paudyal G, et al. Prevalence and pattern of vitreo-retinal diseases in Nepal: the Bhaktapur glaucoma study. BMC Ophthalmol. 2013;13:9.

14. Wasfi El, Sharma R, Powditch E, Abd-Elsayed AA. Pattern of eye casualty clinic cases. Int Arch Med. 2008;1:13.

15. Wang Y, Hunt K, Nazareth I, Freemantle N, Petersen I. Do men consult less than women? An analysis of routinely collected UK general practice data. BMJ Open. 2013;3:e003320.

16. Thompson AE, Anisimowicz Y, Miedema B, Hogg W, Wodchis WP, Aubrey-Bassler $K$. The influence of gender and other patient characteristics on health careseeking behaviour: a QUALICOPC study. BMC Fam Pr. 2016;17:38.

17. Bertakis KD, Azari R, Helms LJ, Callahan EJ, Robbins JA. Gender differences in the utilization of health care services. J Fam Pr. 2000;49:147-52.

18. Hohn A, Gampe J, Lindahl-Jacobsen R, Christensen K, Oksuyzan A. Do men avoid seeking medical advice? A register-based analysis of gender-specific changes in primary healthcare use after first hospitalisation at ages $60+$ in Denmark. J Epidemiol Community Health. 2020;74:573-9.

19. Mozaffarieh M, Sacu S, Benesch T, Wedrich A. Mental health measures of anxiety and depression in patients with retinal detachment. Clin Pr Epidemiol Ment Health. 2007:3:10.

20. Weger M, Pichler T, Franke GH, Haas A, Thaler HV, Kraigher-Krainer N, et al. Assessment of vision-related quality of life in patients with central retinal artery occlusion. Retina 2014;34:539-45.

21. Liddle J, Bartlam R, Mallen CD, Mackie SL, Prior JA, Helliwell T, et al. What is the impact of giant cell arteritis on patients' lives? A UK qualitative study. BMJ Open. 2017;7:e017073.

22. Meacock R, Anselmi L, Kristensen SR, Doran T, Sutton M. Higher mortality rates amongst emergency patients admitted to hospital at weekends reflect a lower probability of admission. J Health Serv Res Policy. 2017;22:12-9.

23. Baker C. Accident and Emergency statistics: Demand, Performance and Pressure. Briefing paper number 6964, 21 February 2017. [Available from: https:// commonslibrary.parliament.uk/research-briefings/sn06964/].

24. Fenton S, Jackson E, Fenton M. An audit of the ophthalmic division of the accident and emergency department of the Royal Victoria Eye and Ear Hospital, Dublin. Ir Med J. 2001;94:265-6.

25. Kadyan A, Sandramouli S, Caruana P. Utilization of an ophthalmic casualty-a critical review. Eye (Lond). 2007;21:441-2.

26. Fea A, Bosone A, Rolle T, Grignolo FM. Eye injuries in an Italian urban population: report of 10,620 cases admitted to an eye emergency department in Torino. Graefes Arch Clin Exp Ophthalmol. 2008;246:175-9.
27. Perumal D, Niederer R, Raynel S, McGhee CN. Patterns of ophthalmic referral and emergency presentations to an acute tertiary eye service in New Zealand. N. Z Med J. 2011;124:35-47.

28. Haring RS, Canner JK, Haider AH, Schneider EB. Ocular injury in the United States: emergency department visits from 2006-2011. Injury 2016;47:104-8.

29. Desai $P$, Morris DS, Minassian DC, MacEwen CJ. Trends in serious ocular trauma in Scotland. Eye (Lond). 2015;29:611-8.

30. Thompson GJ, Mollan SP. Occupational eye injuries: a continuing problem. Occup Med (Lond). 2009;59:123-5.

31. Ramirez DA, Porco TC, Lietman TM, Keenan JD. Ocular injury in United States emergency departments: seasonality and annual trends estimated from a nationally representative dataset. Am J Ophthalmol. 2018;191:149-55.

32. Mitchell $\mathrm{R}$, Curtis K, Fisher M. Understanding trauma as a men's health issue: sex differences in traumatic injury presentations at a level 1 trauma center in Australia. J Trauma Nurs. 2012;19:80-8.

33. Stergiou-Kita M, Mansfield E, Bezo R, Colantonio A, Garritano E, Lafrance M, et al. Danger zone: men, masculinity and occupational health and safety in high risk occupations. Saf Sci. 2015;80:213-20.

34. MacEwen CJ, Baines PS, Desai P. Eye injuries in children: the current picture. $\mathrm{Br} J$ Ophthalmol. 1999;83:933-6.

35. Poyser A, Deol SS, Osman L, Kuht HJ, Sivagnanasithiyar T, Manrique R, et al. Impact of COVID-19 pandemic and lockdown on eye emergencies. Eur J Ophthalmol. 2020 Nov:1120672120974944. https://doi.org/10.1177/1120672120974944

\section{ACKNOWLEDGEMENTS}

MGT is supported by the National Institute for Health Research (NIHR, CL-2017-11003). HJK is supported by Medical Research Council (MRC), London, UK (MC PC 17171). The sponsor or funding organization had no role in the design or conduct of this research

\section{AUTHOR CONTRIBUTIONS}

$D S, A S, J B$, and SV were responsible for study conceptualisation and design. IDS, AS, JYK, RC, SA, RP, FB, RR, PD, FW, BW, LC, DS, FD, BEECS study group, JB and SV were responsible for data collection. IDS, MGT, $A S, H J K$, and JB were responsible for data analysis and interpretation. JYK, RC, RP, FB, and RR contributed to the literature review. IDS, MGT, AS, and JB prepared the original draft of the paper. All authors contributed to critical review, editing, and revisions of the paper.

\section{FUNDING}

MGT is supported by the National Institute for Health Research (NIHR, CL-2017-11003). HJK is supported by Medical Research Council (MRC), London, UK (MC PC 17171). The sponsor or funding organization had no role in the design or conduct of this research. Supplementary information is available on Eye's website.

\section{COMPETING INTERESTS}

The authors declare no competing interests.

\section{ADDITIONAL INFORMATION}

Supplementary information The online version contains supplementary material available at https://doi.org/10.1038/s41433-021-01849-8.

Correspondence and requests for materials should be addressed to lan De Silva.

Reprints and permission information is available at http://www.nature.com/ reprints

Publisher's note Springer Nature remains neutral with regard to jurisdictional claims in published maps and institutional affiliations.

\section{BEECS STUDY GROUP}

Kiran Ahmed ${ }^{15}$, Sarah Anderson ${ }^{9}$, Freddy Beer ${ }^{6}$, Priya Bhatt ${ }^{11}$, John Buchan ${ }^{12,13}$, Adam Bull ${ }^{11}$, Ritu Chaturvedi ${ }^{4}$, Lucy Clarke ${ }^{8}$, Ian De Silva ${ }^{1}$, Felipe Dhawahir-Scala ${ }^{4}$, Polly Dickerson ${ }^{10}$, Gabriela Grimaldi ${ }^{3}$, Alka Gupta ${ }^{9}$, Jae Yee Ku ${ }^{4,5}$, Helen J. Kuht ${ }^{1,2}$, Ketan Limbachia ${ }^{14}$, 
Emma Linton ${ }^{11}$, Aayesha Malik ${ }^{13}$, Mohammud Musleh ${ }^{15}$, Jonathan $\mathrm{Ng}^{11}$, Nikita Nighoskar ${ }^{10}$, Radhika Patel ${ }^{7}$, Romeela Rana-Rahman ${ }^{8}$, Ibrahim Sheriff ${ }^{3}$, Amy-lee Shirodkar ${ }^{3}$, Dilani Siriwardena ${ }^{3}$, Tooba Sohail ${ }^{9}$, Mervyn G. Thomas ${ }^{1,2}$, Seema Verma ${ }^{14}$, Giulio Volpe ${ }^{3}$, Francine Walsh ${ }^{11}$ and Ben While ${ }^{7}$

${ }^{15}$ Ophthalmology Department, Bradford Royal Infirmary, Duckworth Lane, Bradford BD9 6RJ, UK. 